\title{
Pharmacy dispensing patterns and out of pocket expenditure to the patient for generic prescriptions of psychotropic medicines: A survey from 5 locations in Sri Lanka
}

\author{
Ellepola Arjuna ${ }^{1}$, Dharmawardene Vajira ${ }^{2}$, Ellepola Anuradha ${ }^{3}$ \\ Key words: Access to medicines, Out of pocket expenditure, Generic Prescribing, Dispensing
}

\begin{abstract}
Background: A crucial element that restricts access to medicines is price. Generic drugs provide the opportunity for major savings in out of pocket healthcare expenditure since they may be substantially lower in price. However when a generic drug is prescribed, pharmacist decides which brand of the drug to be dispensed. This results in patients paying for single drug at markedly different prices.
\end{abstract}

Aims: To compare costs patient has to bear for psychotropic drugs fluoxetine and risperidone when a generic prescription is presented to a pharmacy.

Methods: Pharmacies in 5 urban locations (Kurunegala, Kandy, Anuradhapura, Puttalam, Mahiyangana) in Sri Lanka were evaluated. A generic prescription for Fluoxetine $20 \mathrm{mg}$ and Risperidone $2 \mathrm{mg}$ was presented to retail pharmacies and received medications were analyzed for the specific brands dispensed and costs incurred.

Results: Price of a fluoxetine $20 \mathrm{mg}$ capsule ranged from Rs. 1.72 to Rs. 30.00 and price of risperidone $2 \mathrm{mg}$ tablet was from Rs 1.15 to Rs. 23.00. Combined monthly cost for the medications ranged from Rs 86.10 to Rs 1803.00 . Approximately $80 \%$ prescriptions received brand preparations expensive than the cheapest brand among them. Lowest cost risperidone was dispensed only in $18 \%$ of instances. Lowest cost fluoxetine was dispensed only in $24 \%$ of instances.

Conclusions: $80 \%$ of the time patients who get generic psychotropic prescriptions pay more than the cost of the lowest cost product. Knowledge about the price ranges of brands available in market could help in reducing the out of pocket expenditure for pharmaceuticals.

\section{Introduction}

In most high-income countries insurance covers the major part of medicine costs to the patient. Howeverin low and

1 Consultant Psychiatrist, Base Hospital, Dambulla.

2 Consultant Psychiatrist, District General Hospital, Matara.

3 Consultant Psychiatrist Teaching Hospital, Anuradhapura

https://orcid.org/0000-0002-3144-710X middle income countries, out of pocket expenditure for medicines can dominate households' spending, coming only second to food. ${ }^{1}$

A Significant proportion of patients in these countries buy their medication supply from private pharmacies. The reasons for this include opting for private consultation due convenience or perceived to be high quality, ability to develop a close therapeutic alliance with one doctor, ${ }^{2}$ doubts about the quality of medications, non availability or limited options in government sector. Therapeutic alliance and availability of multiple medication options may be more important in management of psychiatric patients. $^{3}$

In Sri Lanka approximately $50 \%$ of Total health care costs are born by patients' out of pocket expenditure. On average, $65 \%$ of Sri Lankan households spend private money for health care services. ${ }^{4}$

Cost of medicines is one of the most important components of health expenditure and an obstacle to access.With diminishing incomes and increased inequity, it is important that medicines are affordable. ${ }^{5}$

A medication could be prescribed in Innovator brand name, non propriety name or in brand generic names. In Sri Lanka it is rare for innovator brands to be available or prescribed; most of the prescriptions are written in branded generic names. ${ }^{6}$ These are drugs with names given by companies other than the innovator company. For a given pharmaceutical preparation many marketed brand generics are available and there is a wide price difference. Prescriptions sometimes contain instructions like 'do not substitute', directing pharmacist to prescribe a particular brand.

When a specific brand is unavailable the pharmacist could ask the patient whether a substitute brand is acceptable. When a non proprietary generic prescription is issued, pharmacist has the option of selecting any brand irrespective of cost unless patient specifically asks for a lower priced product. In most instances pharmacist does not communicate with the patient and patient is unaware of the process involved.

Though many brand namedmedicines have cheaper substitutes that are therapeutically and biochemically equivalent, patients do not automatically receive them 
at the pharmacy even when a prescription with a non proprietary name is produced.

This study was planned to study the dispensing practices of the pharmacies when patients bring a non proprietary generic prescription.

\section{Methods}

A generic prescription containing two commonly prescribed psychotropic medications; risperidone $2 \mathrm{mg}$ once daily at night and fluoxetine $20 \mathrm{mg}$ once daily in the morning for 1 week were presented to pharmacies by volunteers. The prescription did not contain any other instructions. The volunteers who visited the pharmacies paid for the medications and collected a receipt and handed over the medication supply and the receipt to the researcher. The researcher noted down the following information for each pharmacy.

Table 1: Information recorded for each pharmacy

\begin{tabular}{|l|l|l|}
\hline & $\begin{array}{l}\text { Fluoxetine } \\
\mathbf{2 0} \mathbf{~ m g}\end{array}$ & $\begin{array}{l}\text { Risperidone } \\
\mathbf{2 ~} \mathbf{~ g g}\end{array}$ \\
\hline $\begin{array}{l}\text { Brand of the medication } \\
\text { dispensed }\end{array}$ & & \\
\hline Price of a tablet or capsule & & \\
\hline $\begin{array}{l}\text { Monthly cost for the medica- } \\
\text { tion }\end{array}$ & & \\
\hline
\end{tabular}

The study was conducted in following five urban/ semi urban locations in Sri Lanka: Kurunegala, Kandy, Anuradhapura, Puttalam and Mahiyangana. Only the Pharmacies located within the $1 \mathrm{~km}$ distance from main government hospital were evaluated. The study was conducted during the December 2014 and January 2015.

\section{Results}

Total of 57 pharmacies were assessed, the number of pharmacies assessed in each town is as follows:
Table 2; Number of pharmacies assessed in each location

\begin{tabular}{|l|l|}
\hline Town & Number of pharmacies assessed \\
\hline Anuradhapura & 12 \\
\hline Kandy & 17 \\
\hline Kurunegala & 16 \\
\hline Mahiyangana & 5 \\
\hline Puttalam & 7 \\
\hline
\end{tabular}

Both the medications were available in all the pharmacies sampled.None of the medications were dispensed in non branded generic name or in innovator brand name. Except for 2 pharmacies in Anuradhapura, each branded generic product was sold at a fixed price.

Majority of the time, a chosen brand was dispensed by pharmacy, without mentioning the availability of alternate cheaper options. On 3 occasions, volunteers were told a particular brand was better than cheaper alternate brand.

For fluoxetine 6 branded generics were recorded and for risperidone there were 4 .

Price of a fluoxetine $20 \mathrm{mg}$ capsule ranged from Rs. 1.72 to Rs. 30.00 whereas that of risperidone ranged from Rs 1.15 to Rs. 23.00 .

Approximately $80 \%$ prescriptions received brands that were expensive than the cheapest available brand (Table 3). Lowest cost brand of risperidone was dispensed only in $18 \%$ of instances. Lowest cost fluoxetine was dispensed only in $24 \%$ of instances. A specific brand of risperidone was dispensed in $58 \%$ of instances. Commonest fluoxetine brand was dispensed in $39 \%$ of instances.

Combined monthly cost for a prescription containing both medications ranged from Rs 86.10 to Rs 1803.00 equaling 20 times price difference. Compared to National Minimal Wage of an individual in Sri Lanka, this expenditure ranged from less than $1 \%$ to $18 \%$ of monthly earnings.

Table 3: Dispensed brands, unit price and the percentage of prescriptions receiving each brand

\begin{tabular}{|c|c|c|c|c|c|}
\hline $\begin{array}{l}\text { Dispensed } \\
\text { Fluoxetine } \\
\text { 20mg Brand }\end{array}$ & $\begin{array}{l}\text { Price of } 20 \mathrm{mg} \\
\text { capsule in } \mathrm{SL} \\
\text { Rupees }\end{array}$ & $\begin{array}{l}\text { Percentage } \\
\text { Dispensed }\end{array}$ & $\begin{array}{l}\text { Dispensed } \\
\text { Risperidone } 2 \mathrm{mg} \\
\text { Brand }\end{array}$ & $\begin{array}{l}\text { Price of } 2 \mathrm{mg} \\
\text { tablet in } \\
\text { SL Rupees }\end{array}$ & $\begin{array}{l}\text { Percentage } \\
\text { Dispensed }\end{array}$ \\
\hline Brand1(Cheapest) & 1.75 & $24 \%$ & Brand1(Cheapest) & 1.15 & $18 \%$ \\
\hline Brand 2 & 3.60 & $39 \%$ & Brand 2 & 6.60 & $58 \%$ \\
\hline Brand 3 & 17.33 & $21 \%$ & Brand 3 & 11.75 & $21 \%$ \\
\hline Brand 4 & 3.50 & $6 \%$ & Brand 4 & 23.00 & $3 \%$ \\
\hline Brand 5 & 10.00 & $6 \%$ & & & \\
\hline Brand 6 & 9.60 & $3 \%$ & & & \\
\hline
\end{tabular}




\section{Conclusion}

The study shows that there is a preference to dispense certain branded preparations, even when the medication is prescribed in generic form.

Though commonest dispensed brand was not the cheapest, it was not the most expensive either. The reasons for pharmacists opting for a particular brand when prescription is in generic could be could be several. A pharmacist could sincerely believe "low price equals low quality", resulting in reluctance to store or dispense a low priced brand. Alternatively there could be incentives provided by manufacturer for selling a particular brand. ${ }^{7}$

Wider availability or heavy marketing of certain brands over others could have been one reason for the preference for some brands. It is a limitation of this study as we have not looked at the availability patterns of each brand across the pharmacies.

As long as the patient is not aware about the prices ranges of a drug, the dispenser selects a brand that could be more costly to the patient compared to the cheapest available brand.

The cost of medicines has been shown to impact the duration of adherence and ultimately the prognosis. ${ }^{8}$ It is known that patients ask for a shorter supply of medication when the cost is high and depressive disorder increases the risk of cost related non adherence. ${ }^{9}$ If the patients were to receive the cheaper preparation it could be argued the adherence rates would be higher.

After this study was completed, in October 2016, Government of Sri Lanka imposed a maximum price tag on 48 medications and the list includes fluoxetine and risperidone. The government introduced maximum retail price for risperidone was Rs. 9.10 and Rs. 11.00 for fluoxetine. It is notable that ceiling prices imposed are higher than the prices of the cheapest brands available in the market. It would be interesting in our view to compare the effects of these new regulations on cost incurred to patient, compared to our finding here.

Our findings in this study suggest that patient being aware about the price ranges of brands available in market could help in reducing the out of pocket expenditure for pharmaceuticals.

Authors acknowledge helpful comments by $\mathrm{Dr} M C$ Weeerasinghe, University of Colombo in the preparation of this manuscript.

\section{References}

1. Cameron A, Ewen M, Ross-Degan DA et al. Medicine prices, availability, and affordability in 36 developing and middle-income countries: a secondary analysis. The Lancet, Volume 373, Issue 9659, 240 - 249

2. Weerasinghe MC, Fernando DN. Access to care in a plural health system: Concerns for policy reforms. Journal of the College of Community Physicians of Sri Lanka Volume 14, No 1 June, 2009, P 39-45

3. Dharmawardene V, Menkes DB. Psychotropic drugs in low-income countries.The Lancet Psychiatry, Volume 1, Issue 7, 490 - 492

4. Kumara AS,Samaratunge R. Patterns and determinants of out-of-pocket health care expenditure in Sri Lanka: evidence from household surveys, Health Policy and Planning, Volume 31, Issue 8, 1 October 2016, Pages 970-983,

5. World Health Organization and Health Action International (2008) Measuring medicine prices, availability, affordability and price components.

6. 6. Prasad K, Ranasinghe B. Pattern of private sector drug prescription in Galle: A descriptive crosssectional study. Gall Med J. 2006:64-68.

7. Kaplan WA, Ritz LS, Vitello $M$, et al. Policies to promote use of generic medicines in low and middle income countries: a review of published literature, 2000-2010. Health policy 2012; 106(3):211-24

8. Viswanathan $\mathrm{M}$, Golin $\mathrm{CE}$, Jones $\mathrm{CD}$, et al. Interventions to improve adherence to selfadministered medications for chronic diseases in the United States: A systematic review. Ann Intern Med. 2012; 157:785-795

9. Briesacher, BA, Gurwitz, JH, \& Soumerai, SB. (2007). Patients At-Risk for Cost-Related Medication Nonadherence: A Review of the Literature. Journal of General Internal Medicine, 22(6), 864-871. 